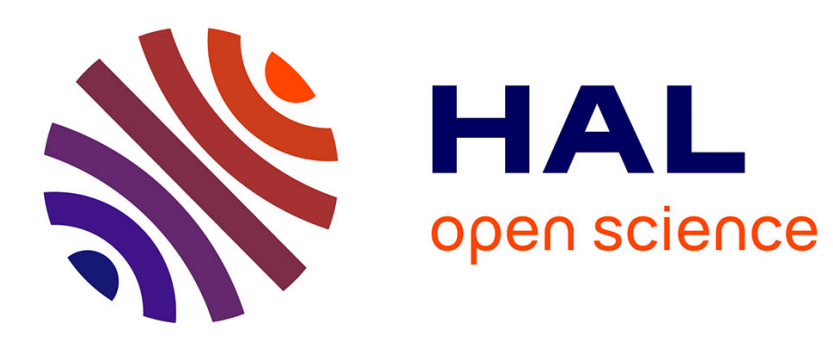

\title{
Simulating the Risks from Aircraft Debris to the Public on the Ground
}

Arnaud Prouzeau, Chris Johnson

\section{To cite this version:}

Arnaud Prouzeau, Chris Johnson. Simulating the Risks from Aircraft Debris to the Public on the Ground. ATACCS 2015 - 5th International Conference on Application and Theory of Automation in Command and Control Systems, Sep 2015, Toulouse, France. 10.1145/2899361.2899372 . hal01649890

\section{HAL Id: hal-01649890 \\ https://hal.inria.fr/hal-01649890}

Submitted on 28 Nov 2017

HAL is a multi-disciplinary open access archive for the deposit and dissemination of scientific research documents, whether they are published or not. The documents may come from teaching and research institutions in France or abroad, or from public or private research centers.
L'archive ouverte pluridisciplinaire HAL, est destinée au dépôt et à la diffusion de documents scientifiques de niveau recherche, publiés ou non, émanant des établissements d'enseignement et de recherche français ou étrangers, des laboratoires publics ou privés. 


\section{Simulating the Risks from Aircraft Debris to the Public on the Ground}

\author{
Arnaud Prouzeau \\ ENAC - UPS \\ Toulouse, France \\ aprouzeau@gmail.com
}

\author{
Chris W. Johnson \\ University of Glasgow \\ Glasgow, UK \\ johnson@dcs.gla.ac.uk
}

\begin{abstract}
The International Civil Aviation Organisation (ICAO) identify an Airprox to be a situation in which, in the opinion of a pilot or air traffic services personnel, the distance between aircraft as well as their relative positions and speed have been such that the safety of the aircraft involved may have been compromised. These are relatively rare events but they must be reported and investigated in order to reduce future risks. Airprox investigations and similar studies into near-miss incidents focus on the risk to passengers and crew. They do not consider the impact of debris. This raises concerns when, for example, the Bijlmermeer crash led to the deaths of 39 people on the ground. This paper presents a system that was developed to simulate the risks from aircraft debris on ground-based infrastructures. The system was developed and validated with help from Airprox investigators. To this end, a User Centered Design process was applied; analysing the activities and needs of potential users from two European investigation agencies. The following pages present the key design decisions, provide insights into the development process and identify limitations with our existing system. The closing sections identify further applications of this approach and suggest areas for further work.
\end{abstract}

\section{Author Keywords}

Human Computer Interaction; Aviation Safety; Airprox; Risk Assessment; Human Factors; Air Traffic Management.

\section{ACM Classification Keywords}

H.1.2 User/Machine Systems: Human Factors; H.5.2: User Interfaces: User Centered Design

\section{INTRODUCTION}

The number of passengers increased by $5 \%$ each year between 2004 and 2013 according to the International Air Transport Association (IATA), but in the same period, the number of accidents fell by $50 \%[2,1]$. In order to maintain such improvements, the International Civil Aviation Organization (ICAO) requires that member states investigate the causes of accidents and of near-miss incidents [14].

Arnaud Prouzeau \& Chris W. Johnson. Simulating the Risks from Aircraft Debris to the Public on the Ground, In ATACCS '15: Proceedings of the 5th International Conference on Application and Theory of Automation in Command and Control Systems, 105-114, ACM, October 2015

(C) ACM, 2015. This is the author's version of the work. It is posted here by permission of ACM for your personal use. Not for redistribution. The definitive version is published in ATACCS 2015, September 30-October 2, 2015, Toulouse, France. $10.1145 / 2899361.2899372$
This paper focuses on the development and validation of a simulation tool to improve our understanding of Airprox incidents. The ICAO define an Airprox to be a situation in which, in the opinion of a pilot or air traffic services personnel, the distance between aircrafts as well as their relative positions and speed have been such that the safety of the aircrafts involved may have been compromised [15]. It is important to study the causes of these near-miss incidents because safety improvements have reduced the number of accidents to the point where they cannot easily guide pro-active risk assessment $\left(1.5 \times 10^{-8}\right.$ fatal aircraft accidents per flying hour in en route flight in controlled airspace [5]). We must look to the higher numbers of incidents if we are to identify potential vulnerabilities in both air (Traffic Collision Avoidance System - TCAS) and ground (Short Term Conflict Alert - STCA) safety nets [6]. EUROCONTROL, the European organization for Air Traffic Management, published a series of guidelines on incident investigation [18]. In particular, they recommended, "Reconstructions should consider the worst, plausible scenario". In order to learn from near-miss incidents it is important to consider what could have happened if the condition were worst (traffic heavier, worst weather, etc...) so that recommendations help to mitigate any potential adverse consequences. In this paper, we focus on scenarios where a mid-air collision occurs over a populated area creating the potential for ground population casualties.

The Bijlmermeer crash provides important background to our work. This involved an El Al Boeing 747 cargo plane; although this was not an Airprox it provides a salient warning of the risks in increasingly congested skies around hub airports. The pilots lost the control of the aircraft after the take off when the hydraulic system broke, the plane crashed into a suburb of Amsterdam killing 39 people on the ground [22]. One of the recommendations of the Nederland Aviation Safety Board was to "Expand the training of pilots and ATC personnel to include awareness that in the handling of an emergency situations not only the safety of airplane/passengers but also the risk to third parties especially residential areas should be considered". To address this recommendation, the Dutch Air Navigation Service Provider (ANSP) LVNL set up a tool that shows on-demand, the residential areas on the screen of the controller. Other countries also began to consider third party casualties. For example, NATS in the United Kingdom worked with the Civil Aviation Authority to identify Public Safety Zone (PSZ). A PSZ is an area adjacent to the end of the runway in which the development of land is restricted [23]. In this area, the risk being 


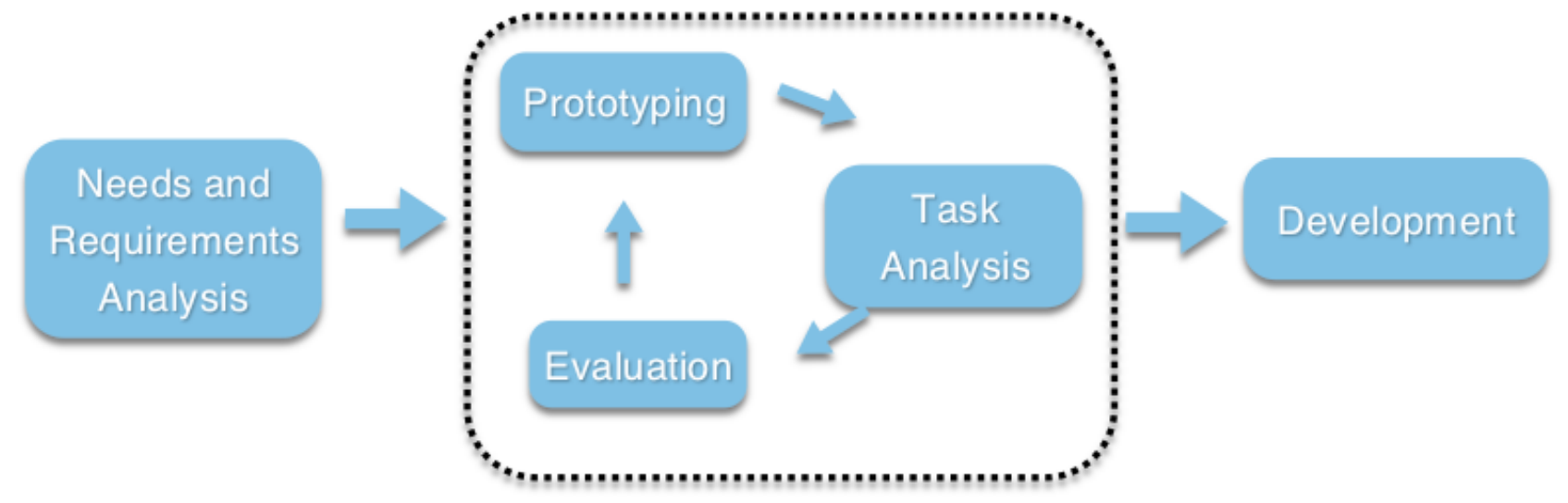

Figure 1. User Centered Design Process Used In The Project

killed as a result of an aircraft accident is estimated to be approximately 1 in 100,000 per year.

The purpose of this project is to help an Airprox investigator assess the risks to the population on the ground. In order to do this, we must assess the potential debris created from a collision and identify the consequences of any potential impact with critical infrastructures, including but not limited to power generation sites, process industries, hazardous storage sites, transport hubs etc. Ulrich Beck stresses the need to carefully considering the presentation of risk-related information [3]. This is particularly important given the difficulty of developing canonical physical models of complex debris fields. We cannot directly calculate the exact path of every component from a mid-air collision down to the ground - accounting for the effects of wind-speed at different altitudes and the surface kinetics, momentum, distribution of hundreds of thousands of objects. Instead, we must rely on proxies that consider the probability of debris landing within particular areas. We, therefore, not only had to consider the development of appropriate kinematic models but also the $3 \mathrm{D}$ visualization that might support Airprox investigators. Further aspects of our research focused on gathering public information about ground-based population distributions and about the location of critical infrastructures across Europe and North America.

This paper will first make a quick summary of the related work, then it will explain the design, implementation and evaluation processes and will finish by presenting the conclusion and the possible future work.

\section{RELATED WORK}

The reconstruction of the event is one of the important phases in an incident investigation, and it is important to give the inspectors tools that they can use to reproduce the context of Airprox incidents. Conventionally, inspectors will gather communication and surveillance data after an incident. This will be supplemented by weather and NOTAM (NOtification To AirMen) data. The pilots and air traffic controllers will also be interviewed, if necessary. After this phase, the inspector is able to analyse the situation. They will assess the situation awareness of the pilots and the workload of the controller. As mentioned previously, however, these investigations seldom explicitly consider the risks for the ground population.

Many European investigation teams rely on radar data to reproduce the air traffic controller screen, showing position, altitude and speed information. This French Mage environment exploits this approach, as does the UK NATS Radar Replay System (NRRS) used by the UK Airprox Board. In order to allow a better visualization of Airprox incidents, the French civil aviation authority (DGAC) developed the EPOQUES tool [12]. This supports two different presentations. These include the classic 2-D radar position visualization, as well as a vertical visualization, and it can also be used to synchronize voice data. The French Aviation University (ENAC) has developed an alternate approach that allows direct exploration of Multi-Dimensional Datasets including Airprox trajectory information [13] There are a small but growing number of 3D reconstruction tools [4]. Most of these are intended for full accident investigations rather than incident analysis because they rely on data retrieved from Flight Data and Cockpit Voice Recorders. However, they can also incorporate weather and ground-based ATM information. Unfortunately, existing visualisation environments cannot easily be used to support Airprox investigations - the focus on supporting accident analysis has led to visualisation that only consider one aircraft rather than the interactions between multiple aircraft that are at the heart of this paper.

None of the tools, listed above, explicitly considers the risk for the ground population. These are further concerns - there is a focus on a specific and defined set of adverse events leading to a near miss or accident. Radar data provides historic information about particular trajectories. In many other contexts, however, it is possible to use computer simulations in a more flexible way. For example, evacuation simulations can be used to consider what might have happened if a fire occurred in another aircraft type. In the earliest stages of our design, we therefore chose to integrate ADS-B data in addition to pre-recorded radar tracks. ADS-B data are data sent by 
planes to ground stations with information about their position, altitude, speed. Not all aircraft are ADS-B equipped, although this will be a requirement for most commercial flights across both Europe and North America within the next five years. A key aim of the approach adopted during the development of our environment was to maximise the use of dynamically updated, publically available data. As we shall see, this same tactic enabled us to benefit from live weather feeds and also dynamic information about both ground population distributions and critical infrastructures. The intention was to enable investigators to insert Airprox incidents into live and emerging traffic patterns across Europe and North America to consider the 'worst plausible circumstances' envisaged in the EUROCONTROL guidance. These conclusions might then be communicated to the local civil aviation authority, to the ANSP and to the airlines.

\section{DESIGN PROCESS}

To design a system that satisfies the needs of the users, in our case Airprox investigators, it is important to consult them during the design phase. It is necessary to understand the tasks that they perform, their workplace, and of course their information needs. A key strength of the project was that the participants combined expertise in Air Traffic Management research and Human Computer Interaction, we therefore followed a User Centred Design process (Figure 1) based on ISO norm 9241-210 [16, 21]. The objectives for this aspect of our work were reaching an explicit understanding of users, tasks and environments, driven and defined by iterative user centered evaluation.

\section{Needs and requirements Analysis}

A key aim of user-centered design is to understand the context of use for any future tool so that it is tailored to the needs of the users. In order to do that, we conducted a number of interviews with investigators from Airprox agencies across two European member states. We also conducted site visits and interviews with the investigatory teams from several European ANSPs. All of the individuals and teams followed a similar approach that can be summarised in Figure 2. Air Accident Investigators, Airport Managers and Safety Analysts were also interviewed, the closing sections will argue that these stakeholders represent possible future users of the simulation environment hence and it was also important to assess their needs.

The first step of an investigation is the notification of an Airprox, for instance by the aircrews or by an Air Traffic Controller. The inspector then has to gather data from the sources mentioned in the previous section to understand the event in its context. The data informs the reconstruction and analysis of a near miss. The results are then documented in a factual report. The final step differs between ECAC states. In some countries, individual inspectors can determine the conclusions and recommendations. In other countries, Airprox boards make these decisions. These boards are composed of stakeholders that include ATCOs and Pilots drawn from both military and civil backgrounds. Finally, the recommendations are sent to national regulatory bodies that will disseminate any lessons and help to monitor their implementation.

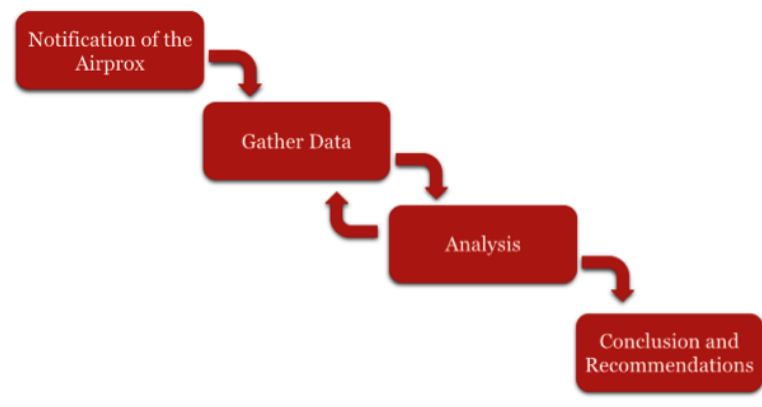

Figure 2. Main Steps In An Airprox Investigation

\section{Prototyping, Task Analysis and Evaluation}

Domain experts across many industries often have little idea of the range of possible, innovative solutions that might be adopted to support their particular tasks. There is often a strong bias towards familiar solutions that are almost the same as previous generations of systems and interfaces [21]. It is for this reason that user centered design advocates an iterative approach, for instance, using prototypes to test initial ideas with stakeholders before moving towards gradual implementation. The prototypes in the first iteration were paper-based (Figure 3 top). The purpose was to quickly evaluate several alternate approaches without focusing on specific implementation details. A Wizard of Oz process were used [19], participants were asked to "think aloud" as the evaluator led them through a potential scenario using the prototype.

The second iteration prototypes used Javascript and JQuery (Figure 3 bottom), with 3D visualizations implemented using Google Earth via the KML language. Again, the purpose was to use lightweight, flexible tools and avoid premature commitment to particular solutions. Finally, the evaluation of the third iteration, described below, was performed with domain experts to validate the insights gained with the earlier prototypes.

\section{Choice of Visualization}

A simple example can be used to illustrate the progress through each of the iterations of our prototypes. Initial designs considered providing detailed numeric assessments of the density of debris in particular geographical regions. The second prototype, illustrated above, used a plane to illustrate the extent of the debris field. However, after stakeholder feedback the final version used different colours to illustrate the density of the debris on the ground [25]. By convention, red indicated a high concentration; yellow an average concentration of debris and green indicated a low density of debris. End users could tailor the precise high, medium and low distribution thresholds in each class through configuration menus. This might seem a trivial design decision but it had important consequences for our visualisation because we then had to super-impose the colour coded debris field onto the population data available for particular geographic locations. This is discussed in the following sections.

A number of different approaches might be used to represent the population, for example: 

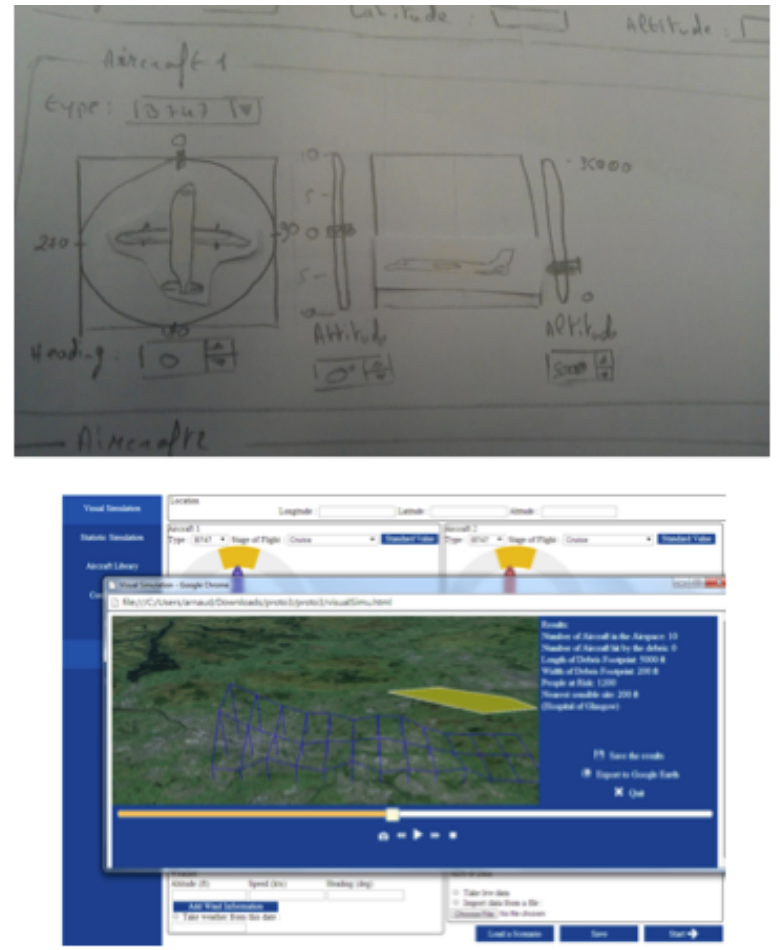

Figure 3. First and Second Iteration Prototypes

- A choropleth map uses colour contrast to represent a statistical variable and has been widely used to represent the population characteristics [17]. However, as described above, our iterative approach led to the use of colour to represent the debris field.

- Kernel Density maps use density estimation functions to map from a finite data sample to provide a more continuous representation that can then be superimposed on a graphical representation of our debris field [27]. The dataset is smoothed, which means that some values will be less accurate. However, this method can suppress noise and allow the user to capture important patterns. For example, with a Kernel density map of population, it can be easier to localize the main city. This kind of map is used when the general trend is more important than exact values. However, in most previous applications density is representing by a colour gradient as with choropleth maps. In consequence, it cannot easily be integrated into our software visualisation.

- A prism map provides a 3D version of a choropleth map (Figure 4 right), it uses the Y-dimension to represent the value of a statistical variable [11]. It can be superimposed on our debris density with colours mapped to an X-plane but can create problems when users have to disambiguate the two values. Further problems relate to the visual clutter with two different values mapped onto different three dimensional structures superimposed on a conventional 3-D geographical map structure [24].

- A spike map is a 3D density map that uses more pronounced peaks in the Z-plan to superimpose a variable onto a geographical map (Figure 4 middle). This visualisation was pioneered Fielding Cage for Time Magazine's population density of the United States of America. However, there are further concerns. The exaggerated use of 3-D peaks exacerbates the problem of occlusion, when a low value is hidden by a high value. Users can overcome this by altering the 3-D view/camera position but this can impose additional navigational burdens.

Acknowledging the potential concerns over visual clutter associated with Choropleth maps to superimpose population and debris distributions, we prototyped the three alternate visualisations illustrated in Figure 4. These integrated population density data from the Gridded Population of the World ${ }^{1}$. We chose to focus on the middle wireframe representation for population density because it minimised the occlusion of debris data, to be mapped by colour distributions on a Y-plane.

\section{DEVELOPMENT PROCESS}

The previous sections have argued that some areas of safetycritical engineering have suffered from a lack of innovation and creativity - we operate systems that are very similar to those that were in use 10 or 20 years ago. The same period has seen radical changes in both information engineering and presentation across a range of consumer-led industries. One aspect of these changes centres on the "internet of things" where physical "real world" objects also have a structured Internet representation that can be used to inform complex decision-making. Ironically, much of the hype has focussed on the control of consumer products including fridges that disclose their contents and heating or security systems that can be activated remotely. However, it was apparent in the early stages of this project that similar information resources might also be used more aggressively to support the development of dynamic, interactive tools for complex, systems engineering. In particular, the intention was to integrate publically available sources of information that in many cases were more accurate than the bespoke services used by Air Navigation Service Providers and by Airprox investigators this included:

- Meteorological data

- Population data

- Geographic information

- Critical infrastructure

- Aircrafts flight plans

All of these pieces of information can be obtained from different public sources across Europe and North America. However, before integrating particular sources into the final tool it was important to identify the criteria that had to be met by particular sources - these include but are not limited to: the reliability of the information (government backed validated source vs commercial vs public); the recency of the data (hourly updates on meteorological servers, population updates every 4-5 years with a national census etc...), the resolution of the information (the compromise between the size 

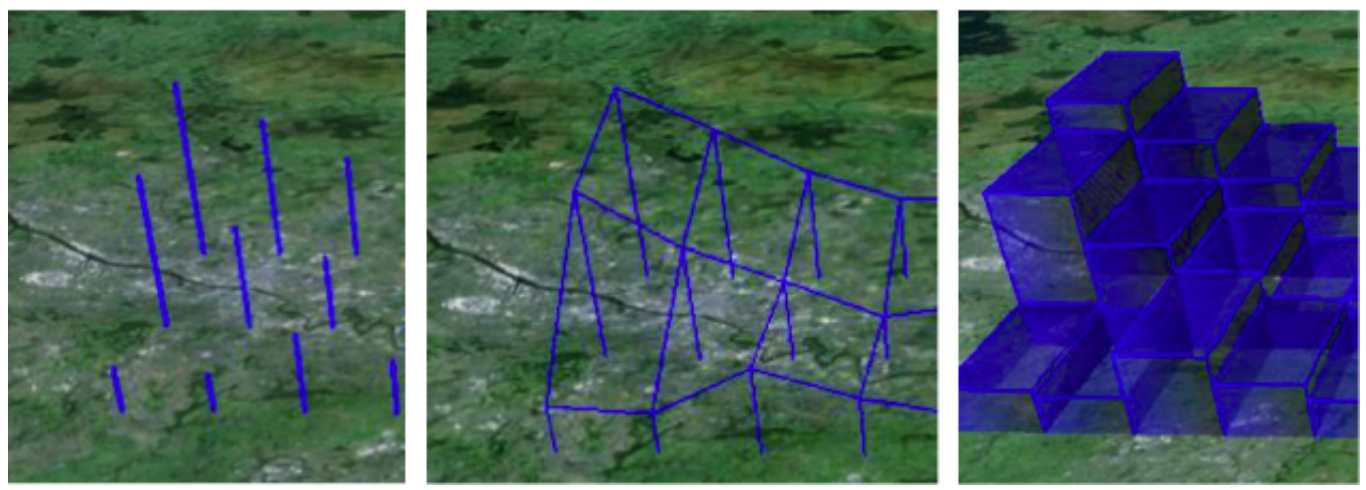

Figure 4. Prototypes of 3 Different Population Visualizations

of the data to be handled and the resolution down to, for instance, 100 kilometer, 10 kilometer or 1 kilometer grids).

\section{Weather}

To calculate the trajectory of the debris after the collision, it is important to know the speed and heading of the wind at different altitudes. Many libraries and websites provide regularly updated weather data. Some of these, such as the US National Oceanic and Atmospheric Agency's Meteorological Data Collection and Reporting System provide real-time updates derived from the on-board equipment carried by aircraft from American, Delta, Federal Express, Northwest, Southwest, United etc. Similar on-line sources exist for regions outside of North America using the Aircraft Communications Addressing and Reporting System. However, as our simulation not only allows users to access live data but also to replay the meteorological conditions at the time when previous Airprox occurred, we required access to an on-line archival service. We, therefore, integrated the forecast.io v2 Forecast Java API ${ }^{2}$. This provides the current weather condition for a given latitude and longitude. It also gives the weather condition for a specific time in the last sixty years for a given latitude and longitude. However, the modular design of our service-oriented application also supports the rapid integration of alternate met services with high resolution or more dynamic update intervals.

\section{Population}

To calculate the population at risk, which is on the key functionalities of this software application, the density of the population in one place was needed. In the previous version of this project it was decided to use the density given by the Gridded Population of the World ${ }^{3}$, a dataset developed by the NASA. It is a database that gives the density of population in the world for a square of 2.5 angular minutes between the latitude 85 North and 58 South. The fact that the size of the area where is given the density of population is known makes the calculus of the population at risk easier. This kind of database is also more convenient to represent it on a map.

\section{Geographic information}

\footnotetext{
${ }^{2}$ https://developer.forecast.io/

${ }^{3} \mathrm{http} / / /$ sedac.ciesin.columbia.edu/
}

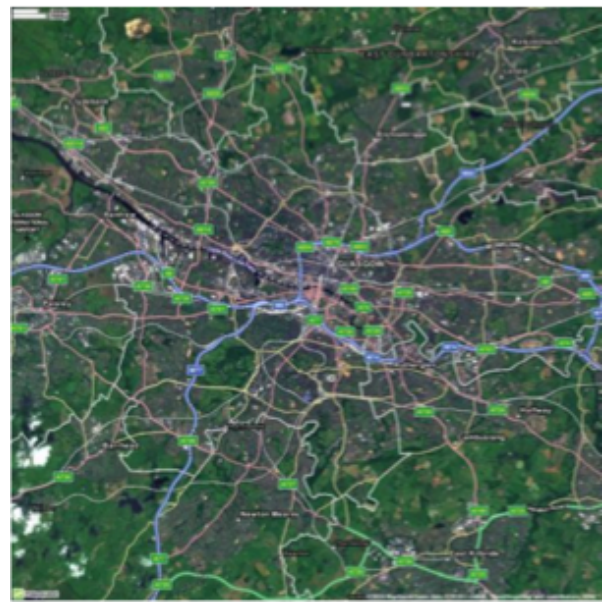

Figure 5. Example of Map Recovered with Mapquest

One of the key components of the simulation is the map imagery. Again, we were anxious to use a geographical information resource that provided high-resolution with recently updated images so that we could trace the extent of any debris field. For this reason, we integrated images provided by the Map Quest web service ${ }^{4}$, illustrated in Figure 5.

The indications (Name and Coordinates) of UK infrastructures were derived from the register maintained under the Control of Major Accident Hazards Regulations (COMAH). Similar resources are appearing on-line across a number of states in Europe and North America. However, there is a tension between the need to disclose information about these sites in order to protect public safety - for instance by alerting citizens to local hazards, and the requirements of national counter-terrorism legislation. This affects the level of detail provided in these information resources.

\section{Aircraft flight plans}

We were concerned to display the flight path of aircraft involved in an Airprox as well as those in the vicinity that might have influenced the course of any incident. In earlier versions of our software, we used FlightAware's FlightXML API ${ }^{5}$. As

\footnotetext{
${ }^{4} \mathrm{http}: / /$ developer.mapquest.com/

${ }^{5} \mathrm{http} / / /$ fr.flightaware.com/commercial/flightxml/
} 
mentioned earlier, this compiles its information from ADS-B servers around the globe. ADS-B is a cooperative surveillance technology for tracking aircraft and unlike secondary radar, does not require expensive ground infrastructures [9]. It is important to stress that this approach again represents a compromise in the design of our simulation tool. Many aircraft in Europe and North America are not yet ADS-B equipped. Ground receivers do not cover many areas. However, EASA and the FAA have both mandated the introduction of this technology and coverage is rapidly improving. There are further problems with the integrity of the data derived in this manner - for example, we have observed aircraft self-reporting at FL-250 but with zero ground speed. In this case, we use extrapolation to estimate a default speed. However, it is important to remember the lack of encryption and of validation for most ADS-B data.

\section{The Debris Model}

To model the impact on the ground population, it is important to calculate the trajectory of debris components. In order to do this, we had to model:

- The generation of debris;

- The trajectory of individual debris components;

- The track and density down to ground level.

The first step of the trajectory calculation is to generate a 'population' of debris from a potential collision. We can then apply a ballistic coefficient adapting existing sources from NASA [7]. The mean and standard deviations for the ballistic coefficient of debris from the NASA catalogue were calculated. This assumed that the coefficients follow a normal distribution. It is important to reiterate that our focus was not on developing new debris models but to find ways of informing the application of existing approaches using diverse publically available information sources. Improving this component of our work remains a priority for future research. However, the approach adopted here has also been adopted in a range of existing commercial tools in other application areas - for example, in planning the 'danger zones' for spectators at air displays.

Once the debris' ballistic coefficients are generated, it is possible to apply Newton's Second Law in 3 dimensions to calculate the acceleration and then the velocity of the debris. Using the Euler method with a time interval, it is possible to determine all the position of the debris as illustrated in Figure 6. A ballistic fall is applied to the debris; its lift is therefore not taken into consideration. However, the geometry of panel components and metal skin structures would have an influence on the debris field especially at higher wind-speeds. The difficulty here is to derive precise information about the break-up patterns of different aircraft types colliding with other aircraft types at different speeds and orientations. Without this data, the introduction of this additional level of detail would be based on narrow speculation and extrapolation from a very small sample.

The descent of the debris assumes a multivariate normal distribution; this supports the calculation of the density function.

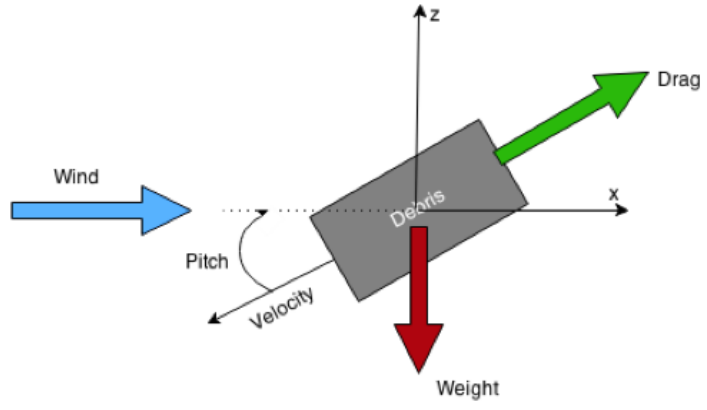

Figure 6. Newton's Second Law Applied To Debris

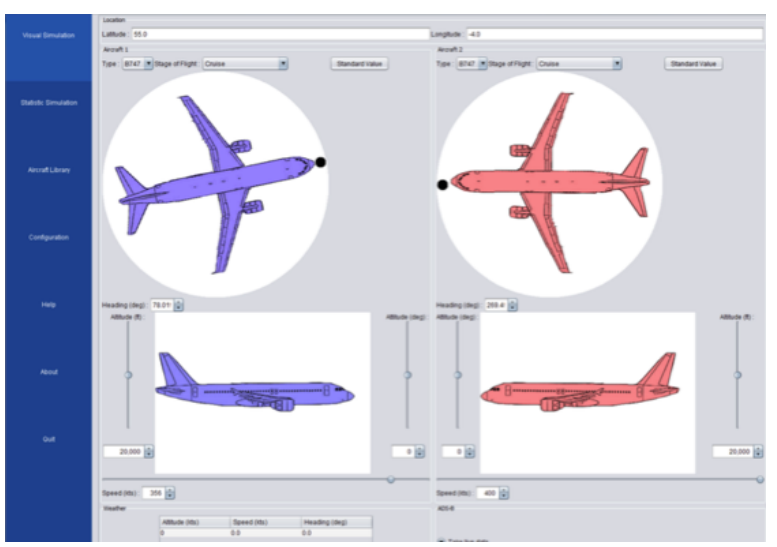

Figure 7. Scenario Preparation Form

However, recent work has explored the use of non-parametric methods using Kernel Density Estimation (KDE) and Local Polynomial Estimation.

\section{Implementation}

Figure 7 provides a screen shot to show how users can prepare the scenarios that might extend previous Airprox incidents for future simulation. For instance, it is possible to alter the closing speeds and altitudes beyond the point at which a midair collision might have been avoided.

Figure 8 shows how the population density is illustrated using the Z-plane, as described in previous sections. In Figure 9, the debris is introduced with colour being calculated as a function of density.

\section{EVALUATION}

Our work was structured using a human-centred development model. It was, therefore, important to demonstrate that the final system met different stakeholders' requirements. We were concerned to test the usability of the software but also to determine whether the tool influenced perceptions about the risks associated with Mid-Air Collisions by explicitly considering the impact on the ground population.

\section{Hypothesis}

To assess the impact of our simulations on risk perception from a Mid-Air collision, we first had to benchmark their 


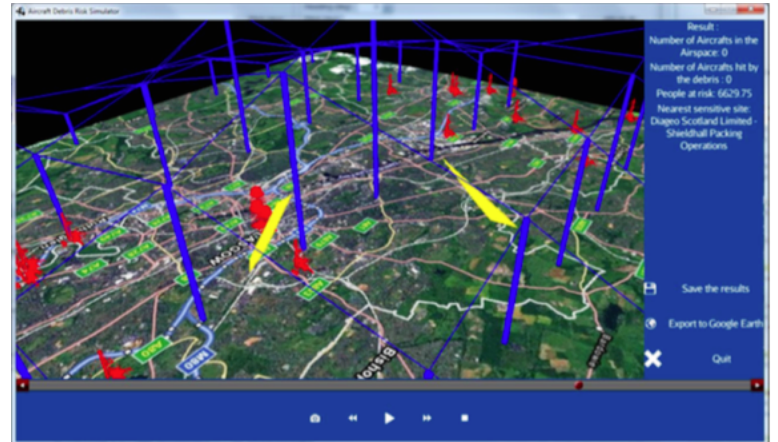

Figure 8. Visualization Of Debris Falling Over a City

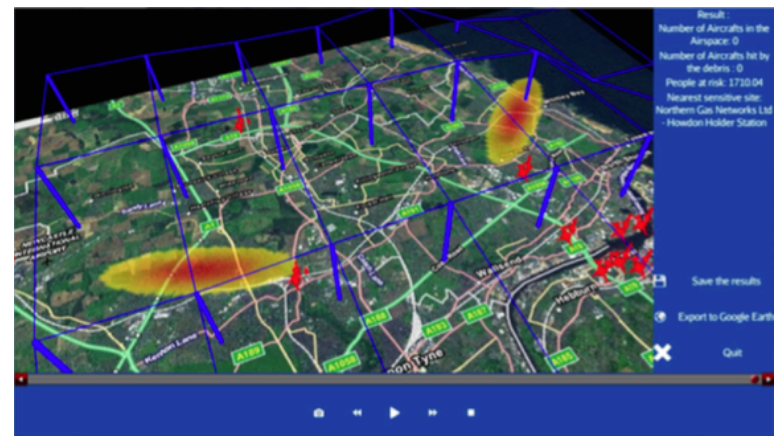

Figure 9. Visualization of The Ground risk from Airprox Incidents

prior perceptions towards these events. Therefore, the null hypothesis of the experience is:

HO: Using the system will not affect the user's risk perception of a mid-air collision impacting the public.

In order to prove this hypothesis, it is necessary to disprove the alternate hypothesis:

H1: Using the system will affect the user's risk perception of a mid-air collision impacting the public.

Our initial evaluation exploited a test designed by Baruch Fischoff [10]; based around nine dimensions that influence risk perception:

- Voluntariness of risk;

- Immediacy of effect;

- Knowledge about risk (by the person exposed);

- Knowledge about risk (by science);

- Control over risk;

- Newness;

- Chronic-catastrophic;

- Common-dread;

- Severity of consequences.

\section{Participants}

Our initial evaluation focussed on six postgraduate students ( 3 males and 3 females). This convenience sample was used prior to more detailed studies involving the potential end users. We chose a more detailed approach - rather than a shorter validation with a larger sample, following the techniques developed by Fischoff.

\section{Procedures}

Two scenarios were presented to the users, as mentioned before, these were extrapolations from previous incidents. The intention behind each simulation scenario was to assess worst plausible consequences as recommended in the EUROCONTROL incident reporting guidelines:

Scenario 1 (based on UK Airprox Report 2012094): happened at a distance of $12 \mathrm{~nm}$ from the centre of Glasgow (lat: 55.86666 and long: -4.08333). A commercial Cessna 560 flying was at its cruise altitude $(18,000 \mathrm{ft})$, on a heading of $355^{\circ}$ at $360 \mathrm{kts}$ when climbing traffic appeared on the TCAS display 5-10 nm in front of him and some 1,200 ft below. When the traffic was less than $1000 \mathrm{ft}$ below, ATC transmitted an avoiding action and the pilot could see the traffic directly in front of him. An Airbus A320 passenger flight was climbing to $25000 \mathrm{ft}$, heading $240^{\circ}$ at $290 \mathrm{kts}$. The weather was calm on the ground with a wind of $10 \mathrm{kts}$, heading $0^{\circ}$. At $20000 \mathrm{ft}$, the wind speed was $50 \mathrm{kts}$, heading $10^{\circ}$.

Scenario 2 (based on UK Airprox Report 2013054): happened over Scotland (lat: 56.7 and long: -4.55) at 34000 $\mathrm{ft}$ and involved two Boeing 747 passenger planes en route across the Atlantic. The first 747 was in a cruise at $480 \mathrm{kts}$, heading $340^{\circ}$, the second at $500 \mathrm{kts}$, heading $300^{\circ}$. At $12 \mathrm{~h} 52$ UTC, an ATCO noticed the two trajectories were converging. They instructed an avoiding action for each aircraft. 4 minutes later, the trajectories were still converging. The ATCO reiterated the avoiding maneuvre. Finally, 2 minutes later, the pilot of one aircraft reported a TCAS resolution advisory. One crew descended while the other went into a climb. The minimum separation distances were $100 \mathrm{ft}$ vertical/3.9 $\mathrm{nm}$ horizontal and 1,100 feet vertical/2.8 nm horizontal. No weather information was available.

\section{$1^{s t}$ Task}

In their first task, users were asked to rate the risk of a midair collision to the local population over a city and over the countryside. For each case, they were asked to rate the nine scales described previously derived from the previous work on more general aspects of risk perception by Fischoff [10].

\section{$2^{\text {nd }}$ Task}

In the second task, users were asked to use the software debris simulation to model the two scenarios. As mentioned before, one justification for the relatively small sample size was the need to train the users in the application of the environment. For the first simulation, they were asked additional subtasks in order to assess the usability:

- Fill the preparation scenario form;

- Save the scenario and reload it; 
Table 1. Results of the Risk Perception Evaluation

\begin{tabular}{|c|l|c|c|}
\hline Location & $\begin{array}{l}\text { Before or Af- } \\
\text { ter the use }\end{array}$ & Average & P-Value \\
\hline \multirow{2}{*}{ Over Glasgow } & Before & 2.7 & 0.5862 \\
\cline { 2 - 3 } & After & 1.7 & \\
\hline \multirow{2}{*}{ Over the countryside } & Before & 2.8 & 0.5807 \\
\cline { 2 - 3 } & After & 3.8 & \\
\hline
\end{tabular}

Table 2. Results of the Usability Evaluation

\begin{tabular}{|c|c|c|}
\hline & & Average \\
\hline \multirow[t]{3}{*}{ Fille the scenario form } & Time & $5 \min 08$ \\
\hline & Mistakes & 1.3 \\
\hline & Easiness & 2.2 \\
\hline \multirow[t]{3}{*}{ Save and load } & Time & $51 \mathrm{~s}$ \\
\hline & Mistakes & 0.2 \\
\hline & Easiness & 1.3 \\
\hline \multirow[t]{3}{*}{ Play the simulation } & Time & $2 \min 36$ \\
\hline & Mistakes & 0.2 \\
\hline & Easiness & 1.5 \\
\hline SUS & & 71.2 \\
\hline
\end{tabular}

- Play the simulation.

For each subtask, they were timed, the mistakes were recognized and the easiness was rated. Finally at the end of these four tasks, the users had to complete a variant of John Brooke's Scale of Usability questionnaire [4].

\section{$3^{\text {rd }}$ Task}

Finally, the users were asked to rate again their perception of the risk of a mid-air collision to the local population over a city and over the countryside, again using the nine scales.

\section{Results}

In order to assess if the use of the Airprox simulation environment does not change users' risk perception about midair collisions, it is necessary to prove that for each question, the answers do not vary between tasks 1 and 3. To do that, a Wilcoxon signed-rank test ${ }^{6}$ [26] was performed for each question. It shows that there is no difference between the risk perception in task 1 and 3, for both mid-air collision over a city or countryside (Table 1). We achieved the same result for 8 of the 9 scales that could influence the perception. The only scale which changed using a $10 \%$ threshold is "Knowledge about risk: To what extent is the risk known to science?", which could be explained by the fact that the simulation itself helps demonstrate that the risk is known to science.

The result of the usability test shows all the three subtasks were completed (Table 2). Finally, the SUS questionnaire yielded a relatively good mean score across the participants of $72 \%$. However, the participants did identify a number of concerns. For instance, several stated that placing the Altitude and Pitch controls on different sides of the same aircraft was confusing. Several of the participants also form it hard to navigate the table used to record Meteorological information.

\footnotetext{
${ }^{6}$ The Wilcoxon signed-rank test is a non-parametric statistical hypothesis test used when the population cannot be assumed to be normally distributed.
}

\section{Discussion}

Our results show that interactive with the Airprox simulator does not change the users' perception of the risks from midair collisions in the two scenarios. One explanation for this is that any form of fatal accident already represents a 'worse case' scenario for our participants. The nine parameters that we considered were not sensitive enough to measure the impact of the additional fatalities. Another interpretation of the results is that they arose from an experimental effect - we were not comparing scenarios in which there were ground casualties and others in which there were not. Instead, we were comparing an initial view of the risks of mid-air collisions with their views after being taken through the simulated scenarios including the ground casualties. Another final consideration is the manner in which the simulation represents the impact of debris on the ground - it may be that a clearer indication of the numbers of people who might be affected would have had a greater impact than the colours used to indicate the debris distribution.

\section{CONCLUSIONS AND FUTURE WORK}

These alternate hypotheses suggest areas for future work. However, external funding pressures have instead directed more of our effort towards two new application areas. The first is concerned less with Airprox events but instead to help ANSPs plan precision approaches using Satellite Based Augmentation Systems such as EGNOS. In the past, Instrument Landing Systems bough aircraft into land on fixed, linear descents. However, the certification of Satellite positioning systems for safety-related applications enables ANSPs to vector aircraft in response to operational requirements - for instance to achieve fuel savings under changing Meteorological conditions. In the past, safety assessments were easily conducted by considering all buildings under the linear ILS approach. With performance-based approaches, our tool provides planners with the information they need to determine what might be under a range of alternate approaches in real-time.

A second application area for the simulation environment is aimed at noise abatement. We are in the process of integrating sound emission models into the system so that we can calculate threshold values for all of individuals on the ground who might be affected by a particular approach at a particular time of the day. The number of people who might be exposed to aircraft noise will change - for example between 10.00 and 22.00. Given our use of geographical modelling tools, we can identify the usage of buildings and begin to calculate exposure levels for particular approaches at particular times of the day. This can again be used in combination with the ground risk assessment models to inform the new generation of SBAS precision approaches [8].

In the future, it is also possible to improve the debris model, by working on the trajectory calculation or in the statistical model used to calculate the density of the debris. The population model can also be improved by developing more dynamic population models to include the ground movement of people over time. Some research has already been performed in this area [20]. 
One of the national Airprox bodies is evaluating the software to assess the ground risk of mid-air collisions at Airprox hotspots in urbanized areas. They are interested both in the population at risk as well as the economic impact. Particular concerns include damage to transportation infrastructures, including motorways or rail junctions.

\section{REFERENCES}

1. ACRO. 2014. Crash Rate per Year - ACRO. Accessed: 2014-08-15. (2014). http: //www . baaa-acro.com/ general-statistics/crashs-rate-per-year/

2. René Amalberti. 2001. The paradoxes of almost totally safe transportation systems. Safety science 37, 2 (2001), 109-126. DOI :

http://dx.doi.org/10.1016/S0925-7535(00)00045-x

3. Ulrich Beck. 1992. Risk Society: Towards a New Modernity, Published in association with Theory, Culture \& Society. (1992).

4. Carole Bolduc and Wayne Jackson. 1999. 3D Animation of Recorded Flight Data. In Transportation Recording: 2000 and Beyond. International Symposium on Transportation Recorders. The National Academies of Sciences, Engineering, Medicine, Arlington, Virginia, 21-28.

5. Peter Brooker. 2006. Air Traffic Management accident risk. Part 1: The limits of realistic modelling. Safety science 44, 5 (2006), 419-450. DOI :

http://dx.doi.org/10.1016/j.ssci.2005.11.004

6. Bundesstelle für Flugunfalluntersuchung. 2004. Investigation Report. Technical Report. BFU.

7. Naval Surface Weapons Center. 1981. Space Shuttle Range Safety Command Destruc System Analysis and Verification - Phase III: Breakup of Space Shuttle Cluster via Range Safety Command Destruct System. Technical Report. Naval Surface Weapons Center. 1-167 pages.

8. ESA. 2009. EGNOS: European Geostationary Navigation Overlay Service. (2009).

9. Eurocontrol. 2013. ADS-B and WAM Implementation in Europe. (2013).

10. Baruch Fischhoff, Paul Slovic, Sarah Lichtenstein, Stephen Read, and Barbara Combs. 1978. How safe is safe enough? A psychometric study of attitudes towards technological risks and benefits. Policy Sciences 9, 2 (1978), 127-152. DOI : http://dx.doi.org/10.1007/BF00143739

11. Randolph Franklin and Harry R. Lewis. 1978. 3-D Graphic Display of Discrete Spatial Data by Prism Maps. In Proceedings of the 5th Annual Conference on Computer Graphics and Interactive Techniques (SIGGRAPH '78). ACM, New York, NY, USA, 70-75. DOI : http://dx.doi.org/10.1145/800248.807373
12. Hélène Gaspard-boulinc, Yannick Jestin, and Lionel Fleury. 2002. EPOQUES: Designing Tools and Methods to Support Incident Investigation in Air Traffic Management. In Workshop on Investigation and Reporting of Incidents and Accidents. ACM, Glasgow, Scotland, 1-9.

13. Christophe Hurter, Benjamin Tissoires, and Stéphane Conversy. 2009. Fromdady: Spreading aircraft trajectories across views to support iterative queries. Visualization and Computer Graphics, IEEE Transactions on 15, 6 (2009), 1017-1024. DOI : http://dx.doi.org/10.1109/TVCG.2009.145

14. International Civil Aviation Organization. 2001. Annex 13 - Aircraft Accident and Incident Investigation. Technical Report 9. International Civil Aviation Organization. 1-42 pages.

15. International Civil Aviation Organization. 2007. Document 4444 - Procedures For Air Navigation Services: Air Traffic Management. Technical Report 1. International Civil Aviation Organization. 1-82 pages.

16. ISO. ISO Norm 9241-210: Ergonomics of human-system interaction - Part 210: Human-centred design for interactive systems. Technical Report. ISO.

17. George F Jenks and Fred C Caspall. 1971. Error on choroplethic maps: definition, measurement, reduction. Annals of the Association of American Geographers 61, 2 (1971), 217-244. DOI : http:

//dx.doi.org/10.1111/j.1467-8306.1971.tb00779.x

18. Chris Johnson, Gilles Le Galo, and Martine Blaize. 2000. Elaboration of Guidelines for ATM Occurrence Investigation. Technical Report. EuroControl. 1-42 pages.

19. J. F. Kelley. 1984. An Iterative Design Methodology for User-friendly Natural Language Office Information Applications. ACM Trans. Inf. Syst. 2, 1 (Jan. 1984), 26-41. DOI : http://dx.doi.org/10.1145/357417.357420

20. Mehdi Khakpour and Jan Ketil Rod. 2013. Developing A Spatio-Temporal Ambient Population Estimation Model using Epidemics-based Geosimulation. AGILE (2013).

21. Célia Martinie, Philippe Palanque, David Navarre, and Eric Barboni. 2012. A development process for usable large scale interactive critical systems: application to satellite ground segments. (2012), 72-93. DOI : http://dx.doi.org/10.1007/978-3-642-34347-6_5

22. Nederlands Aviation Safety Board. 1992. Aircraft Accident Report - El Al Flight 1862. Technical Report. Nederlands Aviation Safety Board. 1-79 pages.

23. Alfred Lambertus Cornelis Roelen. 2008. Causal risk models of air transport: Comparison of user needs and model capabilities. TU Delft, Delft University of Technology, Delft, Nederlands. 
24. James Stewart and Patrick J. Kennelly. 2010.

Illuminated Choropleth Maps. Annals of the Association of American Geographers 100, 3 (2010), 513-534.

DOI :

http: //dx.doi.org/10.1080/00045608.2010.485449

25. Takeshi Takahashi, Keita Emura, Akira Kanaoka,

Shin'ichiro Matsuo, and Tadashi Minowa. 2013. Risk

Visualization and Alerting System: Architecture and

Proof-of-concept Implementation. In Proceedings of the

First International Workshop on Security in Embedded Systems and Smartphones (SESP '13). ACM, New York, NY, USA, 3-10. DOI :

http://dx.doi.org/10.1145/2484417.2484421

26. Frank Wilcoxon. 1945. Individual Comparisons by Ranking Methods. Biometrics Bulletin 1, 6 (1945), pp. 80-83. http: //www. jstor.org/stable/3001968

27. Guiyun Zhou, Jiayuan Lin, and Wenfeng Zheng. 2012. A web-based geographical information system for crime mapping and decision support. In Computational Problem-Solving (ICCP), 2012 International Conference on. 147-150. DOI :

http://dx.doi.org/10.1109/ICCPS.2012.6384228 